\title{
Predisposing factors in microbial keratitis: the significance of contact lens wear
}

\author{
J K G DART
}

From the Department of Clinical Ophthalmology, Moorfields Eye Hospital, City Road, London EC1V 2PD

SUMMARY Fifty-three patients consecutively admitted to Moorfields Eye Hospital for treatment of suspected microbial keratitis were examined to identify predisposing factors. The principal associations were pre-existing corneal disease (22 patients $(41.5 \%))$ and contact lens wear $(22$ patients $(41.5 \%))$. In 13 cases $(25 \%)$ contact lens wear was the only factor in patients with otherwise healthy eyes using contact lenses as an alternative to spectacles. Gram-negative keratitis was more frequent in the lens wearers, with the exception of therapeutic lens users, than in other patients $(\mathrm{p}=0.0006)$ and Pseudomonas aeruginosa caused keratitis in cosmetic soft lens users more frequently $(p=0 \cdot 001)$. There was no correlation between lens handling or solution contamination in three extended wear soft-lens users. This implies that some soft-lens wearers may be infected by Gram-negative organisms from environmental sources other than contaminated lens care materials. Gram-negative keratitis is strongly associated with contact lens wear, and the diagnosis must be considered in any contact lens user with an acutely painful red eye.

Microbial keratitis remains a serious condition with significant morbidity. The predominant causative organisms in the UK are aerobic bacteria, but these and the predisposing factors vary throughout the world. Early diagnosis, identification of the responsible organism, and specific antimicrobial therapy are mandatory for effective treatment. This requires a high index of suspicion for a microbial cause of keratitis and knowledge of the likely causative organisms as well as reliable microbiological investigation and the administration of effective antibiotics in adequate dosages. ${ }^{1}$

Until the use of contact lenses became widespread as an alternative to spectacles microbial keratitis occurred in eyes with existing diseases of the ocular surface that predisposed to infection by disrupting ocular defence mechanisms, ${ }^{2}$ corneal trauma and surgery, postherpetic corneal disease, bullous keratopathy, corneal anaesthesia, corneal exposure, and the dry eye being among the most important. ${ }^{1-4}$ In the past contact lens wearers have made up only a small proportion of patients with this disease. ${ }^{1-4}$ However since $1977^{\circ}$ there have been reports of substantial numbers of cases of bacterial keratitis in wearers of soft contact lenses, mainly from the USA.

Correspondence to J K G Dart, FRCS.
The proportion of microbial ulcers attributed to lens wear has risen to over $30 \%$ in some centres in the $1980 \mathrm{~s},{ }^{67}$ making lens wear one of the major predisposing factors. This has not been the experience everywhere owing to differences in culture, referral pattern, case selection, ${ }^{124}$ and lens wearing patterns. The disease in contact lens wearers is often caused by Pseudomonas aeruginosa, a virulent corneal pathogen,' resulting in severe morbidity. Most of these patients have normal eyes and are wearing lenses as an alternative to spectacles. Concern has been expressed by ophthalmologists ${ }^{8}$ as well as by the lay press in the $\mathrm{UK}^{9}$ and the USA ${ }^{10}$ about this situation.

This prospective study was carried out to provide an up-to-date analysis of the most important predisposing factors and organisms in microbial keratitis at a major centre in the UK and to investigate epidemiological factors in the contact lens wearers.

\section{Patients and methods}

Fifty-three consecutive admissions to Moorfields Eye Hospital for microbial keratitis were assessed in a 10month period between 25 February 1985 and 24 February 1986. Most cases of suspected microbial keratitis are admitted for treatment except those with 
minimal infiltrates not requiring intensive antibiotic therapy. These patients either were already being treated at Moorfields for other conditions when they developed microbial keratitis or presented from the area served by the hospital casualty department, with the exception of one secondary referral from another ophthalmic department. Scrapings from the affected area of cornea were taken routinely by the admitting surgeon for Gram-stain and culture on solid and in liquid media. Identification of the causative organism was confirmed by moderate growth of an organism in the streaks on one solid medium, growth of the same organism in more than one medium, or growth in one liquid medium that correlated with the Gram stain. Cases which did not meet these criteria, but in which a bacterial or fungal cause was treated presumptively were included, as failure to isolate an organism does not rule out a microbial cause. ${ }^{211}$ Patients with a presumptive diagnosis of Herpes simplex virus keratitis were included only if a bacterial superinfection was suspected. The $\chi^{2}$ test and two-tailed Fisher exact probability test were used to analyse proportional data where appropriate.

\section{Results}

CONDITIONS ASSOCIATED WITH MICROBIAL KERATITIS

These are shown in Table 1. Thirty-one cases were unrelated to contact lens wear, and, of these, 22 patients $(41.5 \%$ of the total of 53$)$ had pre-existing ocular surface disorders, $5(9.4 \%)$ had had trauma or surgery, and $4(7.5 \%)$ were a miscellaneous group with other associations. Of the patients in the group with ocular surface disorders, previous Herpes simplex virus keratitis resulting in secondary bacterial or fungal ulcerative keratitis, and bullous keratopathy accounted for over half. Several other conditions were represented among the remaining patients. In the traumatic and surgical group two patients developed keratitis following corneal abrasions, one following graft surgery, and two as a late complication of cataract surgery from abrasions due to loose nylon corneal sutures. There were four patients in the miscellaneous group, none of whom had normal eyes except for one patient with a myeloblastic disorder. Contact lenses were being worn immediately prior to the onset of keratitis in 22 patients $(41.5 \%)$, who were using lenses for the following reasons: cosmetic (as an alternative to spectacles in low hypermetropia and myopia) 10 $(18.9 \%)$, therapeutic (medically supervised treatment for ocular surface disorders) $6(11 \cdot 3 \%)$, aphakia $3(5 \cdot 7 \%)$, and keratoconus $3(5 \cdot 7 \%)$. Extended wear soft contact lenses (EWSCL) were used by 13 patients, daily wear soft contact lenses
Table 1 Summary of patient associations

\begin{tabular}{|c|c|c|c|}
\hline \multicolumn{2}{|l|}{ Associations } & Nos. & Subtotals \\
\hline \multicolumn{2}{|c|}{ Non-users of contact lens } & & $31(58 \cdot 5 \%)$ \\
\hline \multicolumn{2}{|c|}{ Pre-existing corneal disease } & & $22(41 \cdot 5 \%)$ \\
\hline & HSV keratitis & 8 & \\
\hline & Bullous keratopathy & 4 & \\
\hline & Cicatricial conjunctivitis & 2 & \\
\hline & Dry eyes & 2 & \\
\hline & Neurotrophic keratitis & 2 & \\
\hline & Atopic eye disease & 2 & \\
\hline & Leucoma & 1 & \\
\hline & Exposure & 1 & \\
\hline \multicolumn{2}{|c|}{ Trauma/postsurgical } & & $5(9 \cdot 4 \%)$ \\
\hline & Corneal abrasion & 2 & \\
\hline & Lamellar graft & 1 & \\
\hline & Loose cataract sutures & 2 & \\
\hline \multicolumn{2}{|c|}{ Miscellaneous } & 4 & $4(7 \cdot 5 \%)$ \\
\hline & Topical steroid use & & \\
\hline & Blind eye from glaucoma & & \\
\hline & Aphakia & & \\
\hline & Systemic disease & & \\
\hline \multicolumn{2}{|l|}{ Contact lens } & & $22(41 \cdot 5 \%)$ \\
\hline \multirow[t]{3}{*}{ Cosmetic } & & & $10(18.9 \%)$ \\
\hline & DWSCL* & $3(5 \cdot 7 \%)$ & \\
\hline & EWSCL† & $7(13 \cdot 2 \%)$ & \\
\hline Aphakic & DWHCL $\ddagger / D W S C L / E W S C L$ & 3 & $3(5 \cdot 7 \%)$ \\
\hline \multirow[t]{3}{*}{ Keratoconus } & & & $3(5 \cdot 7 \%)$ \\
\hline & DWHCL & 2 & \\
\hline & DWSCL & 1 & \\
\hline \multirow[t]{3}{*}{ Therapeutic } & & & $6(11 \cdot 3 \%)$ \\
\hline & DWHCL & 1 & \\
\hline & EWSCL & $5(9 \cdot 4 \%)$ & \\
\hline Total & & & 53 \\
\hline
\end{tabular}

*Daily wear soft contact lens.

†Extended wear soft contact lens.

$\ddagger$ Daily wear hard contact lens (polymethylmethacrylate and gas permeable).

(DWSCL) by 5 , and daily wear hard contact lenses (DWHCL) by 4 .

No cases occurred in patients without potentially predisposing factors. The only patients with previously normal eyes were the cosmetic lens users and the patient with a myeloblastic disorder.

\section{MORBIDITY}

The age and sex of the study patients are given in Table 2. The cosmetic lens associated group are shown separately; they had otherwise normal eyes and would not have been under hospital supervision had they not developed keratitis. Their outpatient visits and time spent on treatment were directly attributable to the episode of keratitis (Table 2). Loss of vision in this group occurred in three patients with post resolution acuities of $6 / 12,6 / 18$, and perception of light, who claimed to have had normal vision before the episode. The patients in this study occupied a mean of $2 \cdot 1$ beds per day. This was $1 \cdot 8 \%$ of the total number of available beds in the hospital, making this one of the principal causes of admission for medical treatment. 
Table 2 Morbidity

\begin{tabular}{llll}
\hline & & $\begin{array}{l}\text { Cosmetic lens users } \\
(n=10)\end{array}$ & $\begin{array}{l}\text { All patients } \\
(n=53)\end{array}$ \\
\hline Age in years & Range & $16-69$ & $2 \cdot 5-88$ \\
& Mean & $35 \cdot 4$ & 52 \\
Male:female ratio & $4 \mathrm{M}: 6 \mathrm{~F}$ & $30 \mathrm{M}: 23 \mathrm{~F}$ \\
Days in hospital & Range & $3-37$ & $3-37$ \\
& Mean & $9 \cdot 5$ & 12 \\
Out patient visits & Range & $2->16$ & \\
& Mean & 5 & \\
Weeks on treatment & Range & $2->52$ & \\
& Mean & 14 & \\
& & &
\end{tabular}

MICROBIOLOGY

Corneal cultures were positive in 32 patients $(60 \%)$. The frequency of positive cultures was the same in both contact lens and non-contact lens users $(p>0 \cdot 8)$. Corneal isolates from the study patients are shown in Table 3. Non-contact lens users were predominantly

Table 3 Corneal microbial isolates

\begin{tabular}{|c|c|c|c|c|}
\hline \multirow[t]{3}{*}{ Bacteria } & \multicolumn{4}{|c|}{ Numbers } \\
\hline & \multicolumn{3}{|c|}{ Contact lens } & \multirow[t]{2}{*}{ Others } \\
\hline & $S C L^{*}$ & $H C L$ & $T C L \mp$ & \\
\hline \multirow{2}{*}{\multicolumn{5}{|c|}{$\begin{array}{l}\text { Pure infections } \\
\text { Gram-negative }\end{array}$}} \\
\hline & & & & \\
\hline \multicolumn{5}{|l|}{ Pseudomonas sp. } \\
\hline $\begin{array}{l}P . \text { aeruginosa } \\
P \text { fluorescens }\end{array}$ & 4 & & & \\
\hline $\begin{array}{l}\text { P.fluorescens } \\
\text { Unidentified sp. }\end{array}$ & & & & 1 \\
\hline $\begin{array}{l}\text { Unidentified sp. } \\
\text { Moraxella lacunata }\end{array}$ & & & & $\begin{array}{l}1 \\
2\end{array}$ \\
\hline $\begin{array}{l}\text { Moraxella lacunata } \\
\text { Unidentified Gram-neg. bacilli }\end{array}$ & 1 & 1 & & $\begin{array}{l}2 \\
1\end{array}$ \\
\hline $\begin{array}{l}\text { Unidentified Gram-neg. bacilli } \\
\text { Serratia marcescens }\end{array}$ & 1 & 1 & & \\
\hline $\begin{array}{l}\text { Serratia marcescens } \\
\text { Klebsiella oxytoca }\end{array}$ & & & 1 & \\
\hline Proteus mirabilis & & & & 1 \\
\hline \multicolumn{5}{|l|}{ Gram-positive } \\
\hline Staphylococcus pyogenes & & & & 2 \\
\hline Staphylococcus epidermidis & & & 1 & \\
\hline alpha-haemolytic streptococci & & & 1 & \\
\hline beta-haemolytic streptococci & & & & 3 \\
\hline Streptococcus pneumoniae & & & 1 & 2 \\
\hline Diptheroids & & & 1 & 1 \\
\hline \multicolumn{5}{|l|}{ Mixed bacterial infections } \\
\hline \multicolumn{5}{|l|}{ Gram-negative } \\
\hline \multicolumn{5}{|l|}{ Gram-positive and negative } \\
\hline Moraxella+Micrococcus & & & & 1 \\
\hline \multicolumn{5}{|l|}{ Gram-positive } \\
\hline$S$. pyogenes $+S$. viridans & & & & 1 \\
\hline S. epidermidis + alpha- & & & & \\
\hline streptococcus + diptheroid & & & & 1 \\
\hline \multicolumn{5}{|l|}{ Fungal infections } \\
\hline Candida albicans & & & & 1 \\
\hline Aspergillus fumigatus & & & & 1 \\
\hline Subtotals & 6 & 2 & 5 & 19 \\
\hline Total & & & & 32 \\
\hline
\end{tabular}

*Soft contact lenses (all cosmetic daily and extended wear). †Hard contact lenses (aphakia and keratoconus daily wear). $\ddagger$ Therapeutic contact lenses (hard daily and soft extended wear). infected by Gram-positive cocci. The therapeutic contact lens (TCL) users were infected by the same spectrum of bacteria $(p=0 \cdot 391)$. However, the remaining contact lens users differed by being predominantly infected with Gram-negative bacteria when compared with the other patients $(p=0 \cdot 0006)$. Pseudomonas was the commonest Gram-negative bacterial isolate and occurred more frequently in these contact lens wearers $(p=0.009)$, though it was most strongly associated with soft contact lens use $(p=0 \cdot 001)$. Two further cosmetic soft lens wearers, whose corneal cultures were negative, had Pseudomonas recovered from their conjunctiva and contact lens respectively but have not been included in this analysis because they did not meet the criteria for identification of the causative organism.

CONTACT LENS HYGIENE AND ITS CORRELATION WITH OCULAR BACTERIAL ISOLATES

Fourteen contact lens users had their hygiene regimen evaluated by interview and their lens cases and solutions cultured when these could be obtained. The same organism was grown from two DWSCL patients' cases as from their cornea. Three EWSCL patients had not handled their lenses for four to 42 days before the onset of their symptoms. In one of these cases Ps. aeruginosa was isolated from the corneal cultures and in another from the conjunctival cultures only. The third patient had keratitis, typical of Gram-negative infection, from which no organism could be recovered. All the lens solutions and eye drops used by these patients were sterile. The lens case was cultured from the patient with a conjunctival isolate of Pseudomonas but was contaminated with different Gram-negative bacteria.

\section{Discussion}

There have been few studies on the frequency of factors predisposing to corneal ulcers. This study has confirmed that bacterial keratitis is rare in patients with normal eyes ${ }^{1-4}$ except in cosmetic contact lens users, and has shown that the use of contact lenses is now a major predisposing factor in microbial keratitis at one centre in the UK. The proportion of lens wearers affected is the largest reported so far, though there are comparable figures from previous reports in the USA. ${ }^{67} 25 \%$ of the patients in this study were using contact lenses for cosmetic reasons or for aphakia when spectacles or, in unilateral aphakes, an intraocular lens implant would have been an appropriate form of correction. Their episode of keratitis resulted in considerable morbidity. The principal predisposing factors in patients who did not use contact lenses were the same in this study as in those published from similar centres in the last 15 years. ${ }^{1-4}$ 
This study differed from some earlier reports ${ }^{14}$ in that only one patient was a secondary referral for the management of microbial keratitis. All remaining patients were either already being treated at the hospital for predisposing disorders, or were admitted as self referrals or as referrals from general practitioners. These patients are probably typical of those with severe microbial keratitis in any metropolitan region in the UK.

The recovery rate of $60 \%$ for bacteria from corneal cultures is similar to that in other studies, ${ }^{6711}$ as is the similarity in the spectrum of bacteria causing keratitis in therapeutic lens users and non-wearers of lenses. ${ }^{72}$ The high proportion of soft-contact lens wearers infected by Pseudomonas has been noted in all studies reporting substantial numbers of contact lens wearers, ${ }^{471112}$ though Staphylococcus and Gram-negative organisms other than Pseudomonas are also important. ${ }^{5712}$ In this study statistical analysis shows that the frequency of Pseudomonas keratitis in cosmetic and aphakic SCL users is high in comparison with all other patients $(p=0 \cdot 001)$; it did not occur in any of the four HCL users, in which group Pseudomonas has rarely been reported. Infection with other Gram-negative organisms occurred in the $\mathrm{HCL}$ users, and the proportion of infections due to all Gram-negative organisms was higher in all contact lens wearers, except therapeutic, than in the remaining patients $(p=0.0006)$. These findings suggest that the use of any contact lens, except therapeutic, may have modified the spectrum of microbial keratitis found in the general population of people predisposed to the disease, and that soft lens users may be particularly predisposed to infection by Pseudomonas. This is of concern because Pseudomonas is the cause of the most severe fulminating keratitis and because most soft contact lenses are worn for 'cosmetic' purposes.

The risk of microbial keratitis associated with the different predisposing factors cannot be estimated from the type of study reported here because the size of the population at risk is unknown. However, the number of DWSCL and EWSCL users affected was higher than might be expected. $\rightarrow 12$ Although the proportion of microbial keratitis patients using contact lenses is now high at many centres, it must be emphasised that the risk of microbial keratitis to most contact lens users is low. Exceptions are the TCL group, who have ocular abnormalities which predispose them to ocular infection, and the aphakic EWSCL wearers in whom the risk of bacterial keratitis ranges from 1 to $6: 100$ patients per year. ${ }^{13}$ There have been relatively few such studies on other lens types. ${ }^{14-17}$ These are of doubtful value because of uncertainties about the criteria for microbial keratitis, the indications for lens wear, variations in wearing patterns, and the relatively few cases of keratitis reported. In the light of the epidemic of case reports of SCL keratitis it is possible that the upper estimates of microbial keratitis in SCL wear of around 1:1500 per patient year ${ }^{16} 17$ and the lower estimates for HCL wear of between 1:6500 and 1:15500 per eye per year ${ }^{15}$ may be realistic. It is certain that well designed studies need to be done to confirm the magnitude of the relative risk and if possible the absolute risk for cosmetic lens users.

Differences in susceptibility to microbial keratitis for users of different lens types have not been explained. Pseudomonas, like most bacteria, requires an epithelial defect for corneal invasion. ${ }^{\text {i }}$ Such defects occur in all lens wearers at times. ${ }^{15}$ Bacterial contamination of lens care solutions and cases has been shown to occur in normal SCL users ${ }^{19}$ and arises from organisms, including Pseudomonas, that are ubiquitous in our environment. ${ }^{20} \mathrm{It}$ is known that this may result in a large ocular inoculum. Many reports have shown a relationship between the corneal isolate and lens care material contamination, ${ }^{521-23}$ as in the two DWSCL users in this study. Bacteriological typing has confirmed this relationship beyond doubt, ${ }^{20}$ suggesting that improved lens hygiene will decrease the risk of keratitis. ${ }^{19-21}$ However, little emphasis has been given to cases in which no relationship can be shown between the corneal isolate, deficient hygiene, recent lens handling, and solution contamination, even though several studies have recorded such patients. ${ }^{20-24}$ This occurred in three EWSCL users in this study and suggests that contamination of lens care materials may be irrelevant in some patients. This finding, together with the high frequency of Pseudomonas infection in SCL users, is evidence for the hypothesis that some patients wearing SCL may be uniquely susceptible to infection by 'background' levels of contamination from Pseudomonas or other Gram-negatives that do not affect normal people not wearing contact lenses. Recent studies of lens-bacteria interactions have shown that both Gram-positive and Gram-negative organisms may adhere to both hard and hydrogel lens surfaces ${ }^{25}$ and possibly colonise the lens for prolonged periods. ${ }^{26}$ It is probable that lens-eyemicrobial interactions may be of greater importance than has been appreciated. ${ }^{23}$ These may explain some of the findings not explained by the contamination of lens care materials alone.

Now that contact lens wear is the most common predisposing factor for microbial keratitis in patients with previously normal eyes, there is a need for more research into its epidemiology, pathogenesis, and prevention. Meanwhile it is important that Gramnegative keratitis is considered in the differential diagnosis of all patients using contact lenses who 
present with an acutely painful red eye. Early diagnosis and treatment are essential to reduce the morbidity in this potentially blinding disease.

I thank the consultant and resident staff at Moorfields Eye Hospital for facilitating examination of their patients, $M$ Matheson, BSc, for the microbiological data, $R$ Escott and $L$ Jones for clerical assistance, R Buckley, FRCS, Professor B Jay, MD, and Professor G Woodward, $\mathrm{PhD}$, for constructive criticism of the manuscript.

\section{References}

1 Coster DJ, Badenoch PR. Host, microbial, and pharmacological factors affecting the outcome of suppurative keratitis. $\mathrm{Br} J$ Ophthalmol 1987; 71: 96-101.

2 Coster DJ. Inflammatory disease of the outer eye. Trans Ophthalmol Soc UK 1979; 99: 463-80.

3 Brightbill FS. Central corneal ulcers. Ann Ophthalmol 1972; 4: 331-7.

4 Musch DC, Sugar A, Meyer RF. Demographic and predisposing factors in corneal ulceration. Arch Ophthalmol 1983; 101: 1545-8.

5 Cooper RL, Constable IJ. Infective keratitis in soft contact lens wearers. Br J Ophthalmol 1977; 61: 250-4.

6 Galentine PG, Cohen EJ, Laibson PR, Adams CP, Michaud R, Arentsen JJ. Corneal ulcers associated with contact lens wear. Arch Ophthalmol 1984; 102: 891-4.

7 Alfonso E, Mandelbaum S, Fox MJ, Forster RK. Ulcerative keratitis associated with contact lens wear. Am J Ophthalmol 1986; 101: 429-33.

8 Baum J, Boruchoff SA. Editorial: Extended-wear contact lenses and pseudomonal corneal ulcers. Am J Ophthalmol 1986; 101: 372-3.

9 An eye on lenses. The Times (London) 10 January 1986: 9.

10 A skeptical eye on contacts. Time Magazine 27 January 1986: 33.

11 Liesgang TJ, Forster RK. Spectrum of microbial keratitis in South Florida. Am J Ophthalmol 1980; 90: 38-47.

12 Ormerod DL, Smith RE. Contact lens-associated microbial keratitis. Arch Ophthalmol 1986; 104: 79-83.

13 Graham CM, Dart JK, Buckley RJ. Extended wear hydrogel and daily wear hard contact lenses for aphakia. Success and complications in a longitudinal study. Ophthalmology 1986; 93: 1489-94.

14 Dixon JM, Young CA, Baldone JA, Halberg GP, Sampson W, Stone $\mathrm{W}$. Complications associated with the wearing of contact lenses. JAMA 1966; 195: 117-9.

15 Hamano H, Kitano J, Mitsunaga S, Kojima S, Kissling GE. Adverse effects of contact lens wear in a large Japanese population. CLAOJ 1985; 11: 141-7.

16 Roth H-W. Soft hydrophilic contact lenses, results of a long term study. J Jpn Contact Lens Soc 1979; 21: 18-21.

17 Binder PS. Myopic extended wear with the Hydrocurve II soft contact lens. Ophthalmology 1983; 90: 623-6.

18 Stern GA, Lubniewski A, Allen C. The interaction between Pseudomonas aeruginosa and the corneal epithelium. An electron microscopic study. Arch Ophthalmol 1985; 103: 1221-5.

19 Pitts RE, Krachmer JH. Evaluation of soft contact lens disinfection in the home environment. Arch Ophthalmol 1979; 97: 470-2.

20 Mayo MS, Cook WL, Schlitzer RL, Ward MA, Wilson LA, Ahearn DG. Antibiograms, serotypes, and plasmid profiles of Pseudomonas aeruginosa associated with corneal ulcers and contact lens wear. J Clin Microbiol 1986; 24: 372-6.

21 Wilson LA, Schlitzer RL, Ahearn DG. Pseudomonas corneal ulcers associated with soft contact-lens wear. Am J Ophthalmol 1981; 92: 546-54.

22 Patrinely JR, Wilhelmus KR, Rubin JM, Key JE. Bacterial keratitis associated with extended wear soft contact lenses. CLAO J 1985; 11: 234-6.

23 Mondino BJ, Weissman BA, Farb MD, Pettit TH. Corneal ulcers associated with daily-wear and extended-wear contact lenses. Am J Ophthalmol 1986; 102: 58-65.

24 Hassman G, Sugar J. Pseudomonas corneal ulcer with extendedwear soft contact lenses for myopia. Arch Ophthalmol 1983; 101: 1549-50.

25 Dart JKG, Badenoch PR. Bacterial adherence to contact lenses. CLAO J 1986; 12: 220-4.

26 Slusher MM, Myrvik QN, Lewis JC, Gristina AG. Extendedwear lenses, biofilm, and bacterial adhesion. Arch Ophthalmol 1987; 105: 110-5.

Accepted for publication 24 September 1987. 